\title{
A ATUAÇÃo PROFISSIONAL DO PEDAGOGO NO CENTRO DE REFERÊNCIA ESPECIALIZADO DE ASSISTÊNCIA SOCIAL (CREAS)
}

\author{
THE PROFESSIONAL ACTIVITY OF PEDAGOGUE AT THE CENTER OF \\ SPECIALIZED REFERENCE OF SOCIAL ASSISTANCE (CREAS)
}

Márcia Cristiane Ferreira Mendes Mestre em Educação Universidade Estadual do Ceará - UECE. Fortaleza, Ceará, Brasil marciacfmendes@gmail.com

Giovanna Barroca de Moura Mestre em Educação Universidade Federal do Rio Grande do Norte - UFRN. João Pessoa, Paraíba, Brasil giovannabarroca@gmail.com

Tatiana de Medeiros Santos Doutora em Educação Uninassau, João Pessoa, Paraíba, Brasil taty_ms11@hotmail.com

Resumo: Este artigo acadêmico tem como objetivo compreender a atuação do Pedagogo no âmbito da Assistência Social inserido nos Centro de Referência Especializada de Assistência Social, no estado da Paraíba. Para aprofundarmos sobre a temática percorreremos os caminhos da Pedagogia Social, sendo está um reflexo para entender a atuação do educador na Assistência Social - CREAS. Justifica-se a escolha do tema por perceber a importância da formação dos Pedagogos em torno da Pedagogia Social. Como fundamentação teórica apoiamos a pesquisa nas contribuições de Saviani (2013) Paula (2014) Souza, et al (2014), Machado, Rodrigues e Severo (2014), PNAS (2004), LOAS (2003), a Cartilha de Orientação do CREAS (2011), por descreverem os avanços de suas pesquisas no campo educacional e da Pedagogia Social. Como apoio metodológico recorremos a pesquisa de abordagem qualitativa. Ressalta-se ainda que ao longo de todo o trabalho investigativo percebemos a importância de discutir os espaços de atuação do Pedagogo para além dos âmbitos educacionais.

Palavras-chave: pedagogo; pedagogia social; CREAS.

Abstract: This academic article aims to understand the performance of the Pedagogue in the scope of Social Assistance inserted in the Specialized Reference Center for Social Assistance in the state of Paraíba. To better develop the theme, we will follow the paths of Social Pedagogy, which is a reflection to understand the role of the educator in Social Assistance - CREAS. The choice of theme is justified because it perceives the importance of the formation of Pedagogues around Social Pedagogy. As a theoretical foundation, we support the research on the contributions of Saviani (2013) Paula (2014) Souza, et al (2014), Machado, Rodrigues and Severo (2014), PNAS (2004), LOAS (2003) (2011), for describing the advances of their research in the field of education and Social Pedagogy. As a methodological support, we used qualitative research. It is also emphasized that throughout the investigative work we perceive the importance of discussing the Pedagogue's spaces of action beyond the educational scopes.

Keywords: pedagogue; social pedagogy; CREAS.

Para citar - (ABNT NBR 6023:2018)

MENDES, Márcia Cristiane Ferreira; MOURA, Giovanna Barroca de; SANTOS, Tatiana de Medeiros. A atuação profissional do pedagogo no Centro de Referência Especializado de Assistência Social (CREAS). Eccos - Revista Científica, São Paulo, n. 57, p. 1-21, e11581, abr./jun. 2021. Disponível em: https://doi.org/10.5585/eccos.n57.11581. 


\section{Introdução}

Quando se pensa no espaço de atuação do pedagogo, imediatamente vem à tona, no imaginário das pessoas, a sala de aula, sendo esta importante na sociedade e que requer uma qualificação para atuar no âmbito escolar. As Diretrizes Curriculares Nacionais para o Curso de Graduação em Pedagogia, licenciatura (DCNS, 2006), vem dispor exatamente para uma nova visão sobre a atuação do educador que abre possibilidades de atuarem além de ambientes não escolares.

Saviani (2007), em conformidade com a parágrafo anterior, explica que a educação não se reduz ao ensino e não é um fenômeno restrito ao espaço escolar, ela tem como especificidade a seleção e transmissão de diferentes saberes, específicos para cada espaço onde é praticada: família, igreja, sindicato, escola.

Diante desse imaginário (educador e sala de aula) e da atuação do Pedagogo do CREAS, que percebemos a importância de compreender o papel do educador e suas atribuições regimentados para atuar na Assistência Social. Por mais que mencionem sobre a educação nãoformal, a discussão em torno da Educação Social está sendo debatida paulatinamente, o que Souza, et al (2014), menciona que a produção teórica na área aumenta paulatinamente introduzindo subsídios para as reflexões e reivindicações a favor da valorização dos sujeitos que aprendem/ensinam no sistema educacional que não necessariamente é o considerado formal, mas que sem dúvida, existe.

O que estamos colocando também como discussão não é apenas o fato do entendimento quanto a atuação do educador em espaços não escolares refletidos em LDB 9394/96, nos DCNS (2006), mas a formação do Pedagogo e sua inserção na Assistência Social. Para isso alguns questionamentos foram emergindo: Atualmente as universidades estão formando os Pedagogos para atuarem na Assistência Social? Existe uma regulamentação e atribuições formais para o Pedagogo Social atuar no âmbito da assistência social, da mesma maneira que existe para os professores que estão em sala de aula? Esses questionamentos foram importantes para o desenvolvimento da pesquisa, no que buscaremos traçar um estudo sobre a formação do Pedagogo voltado para a sua prática no âmbito da Assistência Social, especificamente no Centro de Referência Especializado de Assistência Social.

Sendo assim, o objetivo do presente estudo é compreender a atuação do Pedagogo no âmbito da Assistência Social inserido nos Centro de Referência Especializada de Assistência Social, no estado da Paraíba. Para aprofundarmos sobre a temática iremos percorrer os caminhos da Pedagogia Social, sendo isto um reflexo para compreender a atuação do educador 
na Assistência Social - CREAS, pautados pelos autores Saviani (2013) Paula (2014) Souza, et al (2014), Machado, Rodrigues e Severo (2014), PNAS (2004), LOAS (2003), a Cartilha de Orientação do CREAS (2011).

A pesquisa como ponto inicial partiu de investigações em sites de periódicos acadêmicos e busca livre (Google), na tentativa de perceber a presença de produções sobre a atuação do Pedagogo no CREAS, utilizando como descritor: "Pedagogia Social e CREAS", refinando pelos últimos cinco anos, em português. A busca pela produção acadêmica sobre a referida temática se deu no banco de periódicos da Coordenadoria de Aperfeiçoamento de Pessoal de Nível Superior (CAPES), onde foram encontrados dois trabalhos intitulados: “A Interdisciplinaridade e o Serviço Social: estudo das relações entre profissões", tal estudo analisa a atuação do assistente social com a equipe técnica do CREAS, especificamente o termo interdisciplinar, não sendo o foco a atuação do Pedagogo e o outro artigo: "Uma didática performativa para educar o corpo" que discute sobre o desempenho da didática para educar, na qual não atendia nossa especificidade de estudo. No Google não foram encontrados nenhum trabalho, e consideramos que, embora os trabalhos selecionados referentes ao tema pelo periódico da CAPES fossem mínimos, o presente estudo torna-se relevante exatamente por essa escassez de pesquisa que discutam sobre a atuação do Pedagogo no Centro de Referência Especializado de Assistência Social.

Nesse entendimento pensamos sobre quais os campos de atuação do Pedagogo, partindo da concepção de que a educação não se limita apenas à escola, uma vez que ao longo da pesquisa dialogaremos com vários autores e documentos legais que mencionam sobre a formação do educador e sua atuação em espaços não formais e sua atribuição no campo da Assistência Social.

\section{Recorte metodológico}

O presente estudo trata de uma pesquisa, que utiliza uma abordagem qualitativa, tendo em vista o caráter pedagógico social de seus objetos complexos e subjetivos referente à atuação do pedagogo no centro de referência especializado de assistência social.

A abordagem qualitativa, muito utilizada no contexto educacional, será destacada neste artigo e o questionário on-line como técnica de coleta de dados. A pesquisa qualitativa busca questões muito específicas e pormenorizadas, preocupando se com um nível da realidade que não pode ser mensurado e quantificado (MINAYO, 2012). Esta autora acrescenta que a pesquisa qualitativa age com base em significados, razões, desejos, crenças, valores, atitudes e 
outras características subjetivas próprias do ser humano que não podem ser limitadas a variáveis numéricas.

Os resultados apreendidos pelo questionário sociodemográfico proporcionam o perfil dos participantes entrevistados para este estudo. Da totalidade da amostra, 9 participantes, 8 são do sexo feminino, 8 possuem graduação completa em Pedagogia, 5 afirmaram que as Universidades preparam os pedagogos para atuarem em espaços não formais e 8 afirmaram que conhecem as atribuições do Pedagogo no âmbito da Assistência social.

Quadro 1 - Perfil dos entrevistados

\begin{tabular}{|l|l|l|l|l|}
\hline Participantes & Gênero & Formação Inicial & $\begin{array}{l}\text { Pergunta 1 } \\
\text { As Universidades } \\
\text { preparam os pedagogos } \\
\text { para atuarem em } \\
\text { espaços não formais? }\end{array}$ & $\begin{array}{l}\text { Pergunta 2 } \\
\text { Você conhece } \\
\text { quais são as } \\
\text { atribuições do } \\
\text { Pedagogo no } \\
\text { âmbito da } \\
\text { Assistência social }\end{array}$ \\
\hline 9 & $\begin{array}{l}8 \text { (Fem.) } \\
1 \text { (Mas.) }\end{array}$ & $\begin{array}{l}8 \text { (superior em Pedagogia) } \\
\text { (pós-graduação) } \\
\text { (Cursando Pedagogia) } \\
\text { 1(Cursando outra licenciatura. }\end{array}$ & $\begin{array}{l}4 \text { (sim) } \\
5 \text { (não) }\end{array}$ & $\begin{array}{l}8 \text { (sim) } \\
1 \text { (não) }\end{array}$ \\
\hline
\end{tabular}

Fonte: Do próprio autor.

Os instrumentos utilizados foram um questionário com três questões abertas e questões fechadas com fim de coletar dados sociodemográfico: idade, sexo, turno de trabalho e escolaridade. As questões abertas com intuito de compreender a prática do Pedagogo mediante os casos que são recebidos pelos CREAS. Tais questões tiveram o objetivo de que os professores respondessem livremente sobre suas práticas e dificuldades encontradas ao atuar no CREAS. Com relação à elaboração das perguntas foram incluídas apenas perguntas relacionadas ao problema pesquisado, que poderiam ser respondidas sem maiores dificuldades e foram evitadas as perguntas que atingissem a intimidade das pessoas (Marconi e Lakatos, 2003).

As perguntas abertas foram as seguintes: descreva a sua compreensão sobre o papel do Pedagogo na Assistência Social e que estão inseridos no CREAS; que tipo de atendimento realiza no Centro de Referência Especializado de Assistência social? (Descrever como são atendidos os casos que chegam ao CREAS pelo pedagogo); que tipo de atendimento realiza no Centro de Referência Especializado de Assistência social? (Descrever como são atendidos os casos que chegam ao CREAS pelo pedagogo).

Para este estudo, entramos em contato, através de e-mail institucional, com os 105 CREAS do Estado da Paraíba, sendo estes municipais e regionais, com um prazo de 10 dias 
para retorno com os questionários respondidos. Como feedback à solicitação: 24 responderam os e-mails enviados, sendo que 15 informaram não haver Pedagogos ou Educadores Sociais na equipe do CREAS e apenas 9 enviaram os questionários respondidos.

A coleta de dados nas escolas se deu da seguinte forma: inicialmente enviamos um email com o Termo de Consentimento Livre e Esclarecido com o objetivo do estudo e instruídos acerca do caráter voluntário e confidencial e o questionário. Caso concordassem em responder seriam disponibilizados os questionários aos envolvidos na pesquisa.

\section{A Pedagogia Social: os espaços não formais de atuação do pedagogo}

A história da educação brasileira nos mostra que a concepção de Pedagogo vem sendo modificada a partir de novas visões de mundo e de sociedade. No cenário atual, século XXI, este profissional passa a ser requisitado em outros espaços de atuação, além dos espaços escolares, sobre o que iremos nos debruçar. A figura do educador era sempre relacionada à sala de aula, sem compreender que sua presença se faz necessária em outros espaços.

(...) há uma certa tradição em nosso país, em que o pedagogo se encaixa apenas no quadro de quem ensina algo apenas para as séries iniciais da escolarização. (...) educação, ensino, dizem respeito a crianças (inclusive porque "peda" do termo Pedagogia é do grego "paidós" que significa criança). Ora, ensino dirige-se a crianças, então quem ensina para crianças é pedagogo. E para ser pedagogo, ensinador de crianças, faz-se um curso de Pedagogia. Foi essa a ideia que permaneceu e continua viva na experiência brasileira de formação de professores. Aliás, a aceitar esse raciocínio, não se sabe por que os cursos de licenciatura também não receberam essa denominação de cursos de Pedagogia. (LIBÂNEO, 1999, p. 02).

A Pedagogia Social surge mediante a problemática do Brasil, salientando que desde o processo de colonização a fragilidade humana se fez presente, e com o passar dos anos foram se agravando, e segundo Souza, et al (2014, p. 80) "com o passar do tempo aqui no Brasil, com a complexidade dos problemas sociais, surge de fato o Educador Social, atuando principalmente no enfrentamento do ciclo de marginalidade e nas camadas populares destituídas de seus direitos básicos", tendo em seus fundamentos a contribuição de Paulo Freire, que defendia a educação popular. Este ainda acreditava que a transformação social só aconteceria através da educação, sendo um instrumento necessário para perceber todas as formas de negação de direito, formando sujeitos críticos e autônomos. Como afirma Machado, Rodrigues e Severo (2014, p.18): 
A contribuição significativa que a Educação Popular traz para essa discussão torna-se fundamental quando se considera que práticas educativas populares surgem a partir das Práticas culturais de cada grupo humano. O acúmulo das produções cientificas da área permite conhecer a fundo as relações educativas próprias do sujeito brasileiro. Algo próximo das discussões antropológicas que podemos identificar com as contribuições das pesquisas desenvolvidas no âmbito da educação Não-Formal, em que considerem as relações educativas presentes nas relações entre os sujeitos com suas diferentes culturas.

Sendo assim, diante desse contexto foi definida, a priori, a Pedagogia Social, tendo em seu objeto de estudo a educação social, reconhecendo seu potencial socializador e de conscientização, diante de grandes problemas sociais. Dessa maneira, Machado, Rodrigues e Severo $(2014$, p.13-14) afirmam que:

O objeto da Pedagogia Social é a Educação Social, o qual define o conteúdo dessa disciplina: a relação da educação com a sociedade. Para desenvolver sistemas teóricopráticos que possam servir de referência para a gestão de práticas educativas nos contextos sociais, a Pedagogia Social conserva em duplo caráter, sendo este geral e específico. $\mathrm{O}$ caráter geral da Pedagogia Social se refere à metateoria que organiza e justifica a constituição de Perspectivas conceituais e matrizes metodológicas para construção e validação do conhecimento que se identifica em seu âmbito. O caráter específico, por sua vez, designa as diferentes abordagens que, plasmando-se ao conceito geral de Pedagogia Social, priorizam distintos aspectos às problemáticas relativas aos sujeitos, contextos socioeducativos e formas de atuação dos educadores sociais.

Uma das dificuldades encontradas hoje (século XXI) é reconhecer a Pedagogia Social como um campo científico, com bases sólidas, tendo um arcabouço teórico que dê conta de todas as discussões em torno dela, como na Espanha, "País em que a Pedagogia Social está afirmada academicamente, gozando de estruturas acadêmicas consolidadas que lhe dão maior margem de maturidade e autonomia cientifica [...]" (MACHADO, RODRIGUES, SEVERO, 2014, p. 13).

Nos âmbitos acadêmicos esse diálogo tem se apresentado paulatinamente, aos poucos, por considerar que tem que ser discutida a temática, mas ainda consideramos que existe falta de compreensão sobre a Pedagogia Social e sua relação com os problemas educacionais do país, o que apontamos ausências de autonomia cientifica. Segundo Machado, Rodrigues e Severo (2014, p.13-14): 
[...] podemos reconhecer que a Pedagogia Social não constitui uma especialidade inscrita no seu âmbito. Essa circunstância não deriva de uma opção de recusa ou negação voluntária de pesquisadores brasileiros, mas parece estar associada a uma falta de tradição acadêmica que vincule os referenciais da Pedagogia Social como aportes de crítica e proposições na realidade educacional do país.

É interessante, ainda, situarmos as relações temáticas propostas no plano das proposições de formação e regulamentação da profissão de Pedagogos e demais educadores para a educação Social, pensando em quais as razões apontam para a importância de que se invista em um novo processo profissionalização no país.

As atuais diretrizes Curriculares Nacionais para os cursos de Pedagogia DCNS (BRASIL, 2006) podem ser consideradas um avanço para a educação, visto que esta abre possiblidades do Pedagogo atuar em outros espaços, mas não dispõe de atribuições e papéis para exercer sua profissão em outros setores. Segundo Machado, Rodrigues e Severo (2014), aponta que mesmo com essa abertura, está ainda desvaloriza a pedagogia que está nas relações sociais e noutras dimensões e processos pedagógicos, também importantes. Como aponta nos DCNS:

Art. $2^{\circ}$ As Diretrizes Curriculares para o curso de Pedagogia aplicam-se à formação inicial para o exercício da docência na Educação Infantil e nos anos iniciais do Ensino Fundamental, nos cursos de Ensino Médio, na modalidade Normal, e em cursos de Educação Profissional na área de serviços e apoio escolar, bem como em outras áreas nas quais sejam previstos conhecimentos pedagógicos. (DCNS 2006, p.11).

Ao se referir à profissionalização do Pedagogo, a Lei de Diretrizes e Bases da Educação (LDB) se organizou para dar forma à educação em seus aspectos estruturais e documentais, fazendo menção ao papel do educador e sua atribuição. Mas ao se tratar da Pedagogia Social este se configura num campo complexo, visto que a sua atribuição fica a cargo de outros órgãos traçarem e delimitarem o seu campo de atuação. Como se configura a seguir:

Art. 61. Consideram-se profissionais da educação escolar básica os que, nela estando
em efetivo exercício e tendo sido formados em cursos reconhecidos, são: I -
professores habilitados em nível médio ou superior para a docência na educação
infantil e nos ensinos fundamental e médio; II - trabalhadores em educação portadores
de diploma de pedagogia, com habilitação em administração, planejamento,
supervisão, inspeção e orientação educacional, bem como com títulos de mestrado ou
doutorado nas mesmas áreas; III - trabalhadores em educação, portadores de diploma
de curso técnico ou superior em área pedagógica ou afim (BRASIL. LDB, 9394/96,
P. 21) Conforme as reflexões de Machado, Rodrigues e Severo (2014, p.13), são necessários uma proposta e planos para a regulamentação da profissão de pedagogos e demais educadores para a Educação Social. No ano de 2009, no estado do Ceará, foi proposto um projeto na Câmara dos Deputados, que atribuía ao Ministério da Educação a incumbência de elaboração de uma Política Nacional de Formação em Educação Social, estabelecendo o ensino Médio como de 
escolarização mínima para o exercício da profissão. Essa exigência mínima abria a possiblidade de uma carreira profissional possibilitando uma titulação maior em cursos superiores, especialização, mestrado e doutorado em Pedagogia, de acordo com Souza, et al (2014).

Essa proposta ainda consta para aprovação da Profissão do Educador Social na comissão de Assuntos Sociais (CAS), com o Projeto de lei do Senado, nº 328 de 2015, autoria do senador Telmário Mota (PDT-RR), conta com relatório favorável do senador Paulo Paim (PT-RS) e deve receber decisão terminativa na CAS. Sua última atualização se deu em sete de fevereiro de 2018, estando pronta para a pauta na Comissão.

\section{CREAS: O Pedagogo e a Assistência Social}

Ao refletir sob os vários espaços de atuação do Pedagogo, especificaremos a do âmbito da Assistência Social, atuando no Centro de Referência Especializado de Assistência Social (CREAS), destacando que este seguirá as orientações da Política Nacional da Assistência Social (PNAS), Lei Orgânica da Assistência Social, no 8.742, de 7 de dezembro de 1993, (LOAS); a Constituição da República Federativa do Brasil de 1988; A carta de Orientação aos técnicos do CREAS.

Assim, faz-se necessário entender a definição do CREAS, segundo as Orientações Técnicas do Centro de referência Especializado de Assistência Social (BRASIL, 2011) define como proteção especial, e sendo uma unidade estatal, pública, que funciona de forma descentralizada, oferecendo serviços e programas no contexto da Política Nacional de Assistência Social, do Sistema Único de Assistência Social e da Tipificação Nacional de Serviços Socioassistenciais.

Seu objetivo é fundamentado no conceito do CREAS que intenciona proteger qualquer pessoa que esteja passando por qualquer situação de violação de direito, planejando, implantando e desenvolvendo ações através de oferta de serviços que venham atender, acompanhar e contribuir de forma efetiva para a proteção da pessoa idosa, pessoa com deficiência, assim como famílias e indivíduos, contra a violação de direitos.

Os serviços do CREAS também se estenderão a situações de risco e violação de direitos de crianças e adolescentes em cumprimento da medida sócioeducativa em meio aberto (Liberdade Assistida e Prestação de Serviços à Comunidade), direcionando o foco das ações para a família, na perspectiva de potencializar sua capacidade de proteção a suas crianças e adolescentes. 
O CREAS deverá ofertar atenções na ocorrência de situações de risco pessoal e social por ocorrência de negligência, abandono, ameaças, maus-tratos, violência física/psicológica/sexual, discriminações sociais e restrições a plena vida com autonomia e exercício de capacidades, prestando atendimento prioritário a crianças, adolescentes e suas famílias nas seguintes situações: crianças e adolescentes vítimas de abuso e exploração sexual; crianças e adolescentes vítimas de violência doméstica (violência física, psicológica, sexual, negligência); famílias inseridas no Programa de Erradicação do Trabalho Infantil que apresentem dificuldades no cumprimento das condicionalidades; crianças e adolescentes em situação de mendicância; crianças e adolescentes que estejam sob "medida de proteção" ou "medida pertinente aos pais ou responsáveis"; crianças e adolescentes em cumprimento da medida de proteção em abrigo ou família acolhedora, e após o cumprimento da medida, quando necessário suporte à reinserção sóciofamiliar; adolescentes em cumprimento de medida socioeducativa de Liberdade Assistida e de Prestação de Serviços à Comunidade; adolescentes e jovens após cumprimento de medida socioeducativa de Internação Estrita, quando necessário suporte à reinserção sóciofamiliar.

Estes serviços devem funcionar em estreita articulação com os demais serviços da proteção social básica e especial, com as demais políticas públicas e demais instituições que compõem o Sistema de Garantia de Direitos, no intuito de estruturar uma rede efetiva de proteção social.

O Pedagogo diferentemente do Assistente Social percebe aspectos educacionais que precisam ser garantidos a criança e ao adolescente, como por exemplo: o direito a educação, a profissionalização e sua inserção na sociedade. Os casos atendidos pelos CREAS perpassaram pela equipe técnica no que são discutidas as demandas recebidas proporcionando uma visão e uma compreensão no que diz respeito a aspectos sociais, legais, psicológicos e educacionais.

Dessa forma, ao evidenciar os papéis e os serviços oferecidos pelo CREAS faz-se necessário atribuir a esses serviços a função do pedagogo, mediante os atendimentos com violação de Direito. A compreensão acerca do papel do Pedagogo na assistência social é baseada pelas publicações e regulamentações disponibilizadas no Ministério do Desenvolvimento Social, vinculado ao governo federal.

O Educador Social ou o Pedagogo foi inserido na Assistência Social da mesma maneira que foi incluído em outros espaços, percebendo a necessidade de contribuições no que se refere aos aspectos pedagógicos, mobilizando assim a sociedade na garantia de direito e perpetuando uma cultura de paz. 
O Conselho Nacional de Assistência Social (CNAS), Resolução nº 9, de 15 de abril de 2014, no art. $4^{\mathrm{o}}$ no inciso II, definiu as funções do Educador Social, a conhecer:

a) desenvolver atividades socioeducativas e de convivência e socialização visando à atenção, defesa e garantia de direitos e proteção aos indivíduos e famílias em situações de vulnerabilidade e/ou risco social e pessoal, que contribuam com o fortalecimento da função protetiva da família;

b) desenvolver atividades instrumentais e registro para assegurar direitos, (re)construção da autonomia, autoestima, convívio e participação social dos usuários, a partir de diferentes formas e metodologias, contemplando as dimensões individuais e coletivas, levando em consideração o ciclo de vida e ações intergeracionais;

c) assegurar a participação social dos usuários em todas as etapas do trabalho social;

d) apoiar e desenvolver atividades de abordagem social e busca ativa;

e) atuar na recepção dos usuários possibilitando ambiência acolhedora;

f) apoiar na identificação e registro de necessidades e demandas dos usuários, assegurando a privacidade das informações;

g) apoiar e participar no planejamento das ações;

h) organizar, facilitar oficinas e desenvolver atividades individuais e coletivas de vivência nas unidades e/ou na comunidade;

i) acompanhar, orientar e monitorar os usuários na execução das atividades;

j) apoiar na organização de eventos artísticos, lúdicos e culturais nas unidades e/ou na comunidade;

k) apoiar no processo de mobilização e campanhas intersetoriais nos territórios de vivência para a prevenção e o enfrentamento de situações de risco social e/ou pessoal, violação de direitos e divulgação das ações das Unidades socioassistenciais;

l) apoiar na elaboração e distribuição de materiais de divulgação das ações;

m) apoiar os demais membros da equipe de referência em todas etapas do processo de trabalho;

n) apoiar na elaboração de registros das atividades desenvolvidas, subsidiando a equipe com insumos para a relação com os órgãos de defesa de direitos e para o preenchimento do Plano de Acompanhamento Individual e/ou familiar; 
o) apoiar na orientação, informação, encaminhamentos e acesso a serviços, programas, projetos, benefícios, transferência de renda, ao mundo do trabalho por meio de articulação com políticas afetas ao trabalho e ao emprego, dentre outras políticas públicas, contribuindo para o usufruto de direitos sociais;

p) apoiar no acompanhamento dos encaminhamentos realizados;

q) apoiar na articulação com a rede de serviços socioassistenciais e políticas públicas;

r) participar das reuniões de equipe para o planejamento das atividades, avaliação de processos, fluxos de trabalho e resultado;

s) desenvolver atividades que contribuam com a prevenção de rompimentos de vínculos familiares e comunitários, possibilitando a superação de situações de fragilidade social vivenciadas;

t) apoiar na identificação e acompanhamento das famílias em descumprimento de condicionalidades;

u) informar, sensibilizar e encaminhar famílias e indivíduos sobre as possibilidades de acesso e participação em cursos de formação e qualificação profissional, programas e projetos de inclusão produtiva e serviços de intermediação de mão de obra;

v) acompanhar o ingresso, frequência e o desempenho dos usuários nos cursos por meio de registros periódicos;

w) apoiar no desenvolvimento dos mapas de oportunidades e demandas.

Toda essa regulamentação contribui para definir as atribuições do Pedagogo ou Educador Social no âmbito da Assistência Social, da mesma maneira que definiu no âmbito Educacional, através da Lei de Diretrizes e Bases da Educação Nacional, 9394/96. O que destacamos a atribuição do Pedagogo dos CREAS, conforme a Orientação Técnicas do Centro de Referência Especializado de Assistência Social (BRASIL, 2011):

[...] afirma que este profissional poderá realizar abordagens de rua e/ou busca ativa no território; receber e acolher criança e adolescente em situação de abrigamento temporário até 2 horas; realizar visitas domiciliares; mapear regiões para identificações dos casos de violência; atender e registrar os casos; fazer a abordagem da família para a sensibilização em relação à necessidade do atendimento; acompanhar in loco a situação de famílias e/ou indivíduos atendidos nas redes de serviços; acompanhar as vítimas no Instituto Médico Legal; acompanhar adolescentes em cumprimento de medidas sócioeducativas em ambiente aberto; participação das atividades de capacitação e formação continuada da equipe do CREAS e as da Secretaria de Estado do Desenvolvimento Humano. Recepção e oferta de informações às famílias do CREAS; Participação das reuniões de equipe para o planejamento de atividades, avaliação de processos, fluxos de trabalho e resultados. 
As principais atribuições de todos que estão inseridos na Assistência Social sendo técnicos de nível superior: Acolhida, escuta qualificada, acompanhamento especializado e oferta de informações e orientações; Elaboração, junto com as famílias/indivíduos, do Plano de acompanhamento Individual e/ou Familiar, considerando as especificidades e particularidades de cada um; Realização de acompanhamento especializado, por meio de atendimentos familiar, individuais e em grupo; Realização de visitas domiciliares às famílias acompanhadas pelo CREAS, quando necessário; Realização de encaminhamentos monitorados para a rede socioassistencial, demais políticas públicas setoriais e órgãos de defesa de direito; Trabalho em equipe interdisciplinar; Orientação jurídico-social (advogado); Alimentação de registros e sistemas de informação sobre as ações desenvolvidas; Participação nas atividades de planejamento, monitoramento e avaliação dos processos de trabalho; Participação das atividades de capacitação e formação continuada da equipe do CREAS, reuniões de equipe, estudos de casos e demais atividades correlatas; Participação de reuniões para avaliação das ações e resultados atingidos e para planejamento das ações a serem desenvolvidas; para a definição de fluxos; instituição de rotina de atendimento e acompanhamento dos usuários; organização dos encaminhamentos, fluxos de informações e procedimentos.

Dessa forma, mesmo com as atribuições definidas, ainda consta para aprovação da Profissão do Educador Social na comissão de Assuntos Sociais (CAS), com o Projeto de lei do Senado, no 328 de 2015, autoria do senador Telmário Mota (PDT-RR), conta com relatório favorável do senador Paulo Paim (PT-RS) e deve receber decisão terminativa na CAS. Sua última atualização se deu em sete de fevereiro de 2018, estando pronta para a pauta na comissão.

A atividade de educador social, desde 2009, foi incluída na Classificação Brasileira de Ocupações do Ministério do Trabalho. E muitos estados já abriram concursos públicos para o provimento de cargos para essa atividade. A atribuição do Pedagogo na Assistência Social e no CREAS fora especificado no Conselho Nacional de Assistência Social, aguardando uma afirmativa no senado, mas consideramos que este esclarecimento é algo que não foi incorporado efetivamente nas rodas de diálogo nas universidades, considerando que os Pedagogos não saem preparados para atuarem nos âmbitos além dos espaços escolares.

\section{Resultado e discussão}

Os resultados apreendidos pelo questionário sóciodemográfico proporcionam o perfil dos participantes entrevistados para este estudo. Da totalidade da amostra, 9 participantes, 8 são do sexo feminino, 8 possuem graduação completa em Pedagogia, 5 afirmaram que as 
Universidades preparam os pedagogos para atuarem em espaços não formais e 8 afirmaram que conhecem as atribuições do Pedagogo no âmbito da Assistência social.

Inicialmente apresentaremos as questões e suas respostas como proposta de reflexão quanto às atribuições do Pedagogo Social no Centro de Referência Especializada de Assistência Social. Em seguida, no Quadro 1, serão evidenciados relatos desses profissionais sobre suas experiências e percepção quanto a atuação do Pedagogo na Assistência.

Quadro 1 - Perfil dos entrevistados

\begin{tabular}{|l|l|l|l|l|}
\hline Participantes & Gênero & Formação Inicial & $\begin{array}{l}\text { Pergunta 1 } \\
\text { As Universidades } \\
\text { preparam os } \\
\text { pedagogos para } \\
\text { atuarem em espaços } \\
\text { não formais? }\end{array}$ & $\begin{array}{l}\text { Pergunta 2 } \\
\text { Você conhece quais } \\
\text { são as atribuições do } \\
\text { Pedagogo no âmbito } \\
\text { da Assistência social }\end{array}$ \\
\hline 9 & 8 (Fem) & $\begin{array}{l}8 \text { (superior em Pedagogia) } \\
4 \text { (pós-graduação) } \\
1 \text { (Cursando Pedagogia) } \\
1 \text { (Cursando outra licenciatura. }\end{array}$ & $\begin{array}{l}4 \text { (sim) } \\
5 \text { (não) }\end{array}$ & 8 (sim) \\
& 1 (não) \\
\hline
\end{tabular}

Fonte: Do próprio autor

Foram realizadas três perguntas, sendo primordiais para compreensão do presente estudo, partindo das experiências dos Pedagogos que atuam na Assistência Social na Paraíba, especificamente no CREAS. Quanto às questões sobre a compreensão sobre a atuação do Pedagogo na Assistência Social oito dos pesquisados afirmaram conhecer, mas a compreensão por vezes não é identificada na prática, visto que a formação do educador na Pedagogia Social nas universidades é pouco explorada. O que cinco dos participantes afirmaram que as universidades não formam para atuar em espaços não formais, sendo que essa realidade diferente no CREAS, pois nas perguntas abertas foi descrita a falta de formação para atuar nesse tipo de atendimento.

A Tabela 1, a seguir, descreve a compreensão dos participantes acerca do papel do Pedagogo na Assistência Social.

Tabela 1 - Descreva a sua compreensão sobre o papel do Pedagogo na Assistência Social e que estão inseridos no CREAS.

\begin{tabular}{ll}
\hline Participante & Resposta \\
\hline Participante 1 & Deve agir com sensibilidade ao abordar o usuário \\
& e no momento da escuta; a ética e o trabalhar em \\
& equipe é imprescindível ao educador no meu \\
ponto de vista é a base de todo o trabalho; ele & precisa no mínimo se apropriar da política da \\
& assistência social, através dos estudos realizados \\
& (Tipificação, LOAS, PNAS, ECA, Estatuto do
\end{tabular}




\section{conclusão}

Idoso, Lei Maria da Penha, Cartilhas de orientação sobre o CREAS, sobre pessoa com deficiência e outros). É importante ressaltar que

\section{Participante 2}

Participante 3

Participante 4

Participante 5

Participante 6

Participante 7

Participante 8

Participante 9 esse estudo deve ser realizado por toda a equipe. O Pedagogo tem a função de compor a equipe multidisciplinar do CREAS, dando suporte pedagógico, principalmente, no atendimento às crianças e adolescentes que, apresentando algum histórico de violação de direitos.

Dar suporte Pedagógico a equipe, fazendo paralelo com os conhecimentos educacionais as ações da assistência.

Neste local são atendidas crianças vítimas de violência física psicológica e negligência. $\mathrm{O}$ pedagogo faz a escuta, conversa com a criança e juntamente com a equipe do Creas realizamos os trabalhos que se faz necessário com ela.

O papel do educador é desenvolver junto com os educandos meios para facilitar a descoberta de novos caminhos, fazer uma consolidação entre educadores e educandos.

Sendo de suma importância, pois visa apoiar e monitorar atividades socioeducativas de convivência e socialização.

Não respondeu

O papel do Pedagogo na Assistência Social é bastante complexo, pois atua no Atendimento/Acompanhamento de Crianças, Jovens, Mulheres e Idosos em Vulnerabilidade Social, como também, na elaboração de Projetos Sociais e Relatórios de famílias Acompanhadas Pelo Centro de Referência. Deste modo, o Pedagogo auxilia na promoção da cidadania e emancipação dos sujeitos usuários do Creas.

O pedagogo deve participar das reuniões de equipe para o planejamento de atividades, avaliação de processos, fluxo de trabalho e resultados. Outro papel do pedagogo é: apoio aos demais profissionais no que se refere às funções administrativas da unidade.

Fonte: Do próprio autor

Nas respostas fornecidas por estes atores sociais percebemos que a definição por várias vezes é apresentada configurada a partir da prática, do que já exerce no CREAS, só a participante 1 que é apontou a "legislação, planos e tipificação. técnica, ao atendimento a criança, atenção a medida socioeducativa, o que é determinado pelo LOAS, PNAS, ECA, Estatuto do Idoso, Lei Maria da Penha, Cartilhas de orientação sobre o CREAS, sobre pessoa com deficiência e outros)", alguns destacam a sua atuação na medida socioeducativa e outros no atendimento. $\mathrm{O}$ que apresenta uma visão diferenciada, mas ao mesmo tempo a percepção 
que o atendimento se refere a todas as pessoas que estão em risco ou estão em situação de violação de direito.

Tabela 2 - Que tipo de atendimento é realizado no centro de referência especializado de Assistência Social? (descrever como são atendidos os casos que chegam ao CREAS, pelo pedagogo)

Continua

\begin{tabular}{ll}
\hline Participante & Resposta \\
\hline Participante 1 & O tipo de atendimento realizado pelo pedagogo \\
& no CREAS é bem diversificado, ou seja, o \\
& pedagogo está sempre com um dos colegas \\
(psicólogo, assistente social, advogado), quando & vão realizar visitas; na busca ativa; na escuta, etc. \\
& Isto porque ao lidar com as demandas que são \\
& direcionadas ao CREAS "VIOLÊNCIAS" o \\
& atendimento deve ser sempre por dois \\
& profissionais do serviço, salvo em algumas \\
& situações, em que o usuário fica mais à vontade \\
& quando se permite ser escutado por apenas um \\
& dos profissionais. Quero reforçar que é \\
indispensável a presença de um pedagogo na \\
equipe.
\end{tabular}

\section{Participante 2}

\section{Participante 3}

\section{Participante 4}

Os casos são acompanhados por toda a equipe. Sendo assim, o pedagogo participa dos estudos de casos e é responsável por fazer os atendimentos educacionais voltados, principalmente, para o público infantil. Tais atendimentos podem ocorrer de forma individualizada ou grupal e tem como espaço específico a Brinquedoteca. Além disso, o Pedagogo atua dando suporte à equipe, na detecção de possíveis violações em desfavor de crianças através do trabalho (brincadeiras, dinâmicas, conversas, Contações de história) desenvolvido com estas crianças.

Visita às famílias, acompanhamento escolar, reuniões socioeducativas e com a família, elaboração de material pedagógico e planejamento.

Neste local são atendidas crianças vítimas de violência física, psicológica e negligência. $\mathrm{O}$ pedagogo faz a escuta e conversa com a criança e juntamente com a equipe do CREAS realiza os trabalhos que se faz necessário com a(s) criança(s). 


\section{conclusão}

Participante 5

Participante 6

\section{Participante 7}

Participante 8

Participante 9
São atendidos crianças e adolescentes, mulheres e pessoas idosas e pessoas que tenham sofrido violação de seus direitos e também família e indivíduos em situação de rua. São atendidas no CREAS por meio do serviço de proteção e atendimento especializado a famílias e indivíduos(paefi).

Realiza-se o acolhimento, mapeamento do perfil do usuário, acompanhamento e encaminhamentos do sócio educandos (LA, PSC), busca ativa, abordagem social.

Brinquedoteca com crianças, palestras, promover busca ativas, atividades de orientação e prevenção, visitas domiciliares, atividades de escutas, etc.

Depois de registrado o caso no Creas, a Equipe Técnica realiza visita domiciliar à família que está em Vulnerabilidade Social, analisa a situação, confecciona um relatório, cria Pasta de Casos, como também, realiza Acompanhamento seja domiciliar ou através de Grupos criados pelo Creas.

São realizadas rodas de conversas, momentos de aprendizagem com jogos educativos, entre outros.

Fonte: Do próprio autor.

Conforme se pode visualizar na Tabela 2, as respostas dos que desempenham as atividades são atreladas à demanda de cada usuário, percebendo a necessidade, mas o que é primordial é a acolhida, a escuta, para dar início a outros procedimentos. Também visualizamos que as respostas, $1,4,5$, explicitam mais o que deve ser feito, muito mais do que estão fazendo. Essa contribuição permite que identifiquemos quais os tipos de atendimentos realizados para poder delinear o papel do pedagogo na assistência na atualidade, partindo de uma visão prática. O que também sentimos ausente nas respostas é a possibilidade de produções cientificas em torno das problemáticas que surgem em torna do CREAS, como também as buscas ativas, conforme a Orientação Técnica do Centro de Referência Especializado de Assistência Social (BRASIL, 2011), na qual aponta as atribuições do Pedagogo e que este, além do que foi descrito na tabela, ainda poderá realizar abordagens de rua e/ou busca ativa no território; receber e acolher criança e adolescente em situação de abrigamento temporário até 2 horas; realizar visitas domiciliares; mapear regiões para identificações dos casos de violência.

Tabela 3 - Como Pedagogo ou Educador Social quais os principais desafios enfrentados na área de Assistência Social? 


\begin{tabular}{|c|c|}
\hline Participante & Resposta \\
\hline Participante 1 & $\begin{array}{l}\text { Bem, esta é uma questão que tem um } \\
\text { entendimento muito pessoal no meu ponto de } \\
\text { vista. Ainda existe algum preconceito entre as } \\
\text { partes, visto que quem é da assistência social se } \\
\text { liga mais ao psicólogo, eis a fala de vários } \\
\text { profissionais dos CREAS. Chegam a dizer que, } \\
\text { quando há determinada formação só inclui o } \\
\text { psicólogo e o assistente social. } \\
\text { Particularmente, não me sinto excluída, sinto que } \\
\text { cada um tem seu papel e sua importância dentro } \\
\text { do serviço. É um quarteto que, quando integrados } \\
\text { fazem a diferença. Infelizmente nem sempre essa } \\
\text { integração acontece, por algumas questões que } \\
\text { são insignificantes: vaidade, orgulho, falta de } \\
\text { compromisso, falta de respeito entre a equipe e } \\
\text { outros. }\end{array}$ \\
\hline Participante 2 & $\begin{array}{l}\text { Apesar de ter, durante o período de formação, } \\
\text { contato com informaçães direcionadas à atuação } \\
\text { do Pedagogo em espaços não formais, o âmbito } \\
\text { da Assistência Social é muito diferente do âmbito } \\
\text { escolar, no qual se concentra a formação durante } \\
\text { a graduação. Sendo assim, existe uma defasagem } \\
\text { na formação do Pedagogo para atuar em outras } \\
\text { esferas que diferem da escolar, de maneira que tal } \\
\text { formação acaba por se efetivar a partir da } \\
\text { vivência. }\end{array}$ \\
\hline Participante 3 & $\begin{array}{l}\text { A falta de informação da sociedade quanto aos } \\
\text { seus direitos e deveres, e o preconceito com os } \\
\text { adolescentes que já cometeram ato infracional. }\end{array}$ \\
\hline Participante 4 & $\begin{array}{l}\text { é fazer com que a criança vítima da violência } \\
\text { volte a ser uma criança normal. }\end{array}$ \\
\hline Participante 5 & $\begin{array}{l}\text { Resgatar pessoas em risco e torná-las ativas, } \\
\text { tarefa muito difícil. }\end{array}$ \\
\hline Participante 6 & $\begin{array}{l}\text { A falta de Políticas Públicas que possibilitem a } \\
\text { profissionalização e inserção no mercado de } \\
\text { trabalho de famílias em situação de } \\
\text { vulnerabilidade. }\end{array}$ \\
\hline Participante 7 & $\begin{array}{l}\text { Acredito que o principal desafio é fazer com que } \\
\text { as pessoas que estão necessitadas de atenção, } \\
\text { coragem, voltem a acreditar nelas mesmas, ou } \\
\text { seja, mudar a vida dessas pessoas através da } \\
\text { educação, esse é sem dúvida o maior desafio } \\
\text { encontrado, porém me sinto realizada com os } \\
\text { inúmeros avanços que já existem. }\end{array}$ \\
\hline Participante 8 & $\begin{array}{l}\text { A carência de recursos; a emancipação dos } \\
\text { sujeitos atendidos pelo CREAS; A solução dos } \\
\text { casos de negligência; O reconhecimento dos } \\
\text { profissionais. }\end{array}$ \\
\hline Participante 9 & Falta de recursos materiais. \\
\hline
\end{tabular}

Fonte: Do próprio autor 
Como se pode ver na Tabela 3, as narrativas que constam na última questão proporcionam uma visão da realidade do atendimento que é oferecido no CREAS, destacando o enfretamento do Pedagogo diante de falta de recursos, formação especifica para atuar no CREAS oferecido pelas instituições educativas, pelos gestores municipais, o reconhecimento como componente atuante da equipe multidisciplinar, a efetivação das políticas de assistência quando se trata da integralização do adolescente à sociedade e o esclarecimento quanto aos direitos e deveres das crianças e adolescentes.

Conforme já descrita sobre a história da Pedagogia Social, sua percepção quanto à ação do educador, deverá estar sempre atrelada ao Social, com cunho educativo e de ressocialização. De atenuar as problemáticas brasileiras, quanto à violação dos direitos de qualquer ser humano. Para tanto, ainda se torna uma tarefa difícil para todos que estão envolvidos em programas e em órgãos de proteção. Essa percepção é apontada diante da última pergunta e os relatos de educadores que estão envolvidos nesse comprometimento de garantir o exercício de forma plena de todos os direitos fundamentais regulamentados na nossa Constituição Brasileira de 1988, de acordo com o Art. 5: "Todos são iguais perante a lei, sem distinção de qualquer natureza, garantindo-se aos brasileiros e aos estrangeiros residentes no País a inviolabilidade do direito à vida, à liberdade, à igualdade, à segurança e à propriedade".

A formação do Pedagogo é de suma importância para atuar na Assistência Social, é preciso conhecer as leis de proteção da criança e adolescentes, como também a Política Nacional da Assistência Social (PNAS), Lei Orgânica da Assistência Social, nº 8.742, de 7 de dezembro de 1993, (LOAS); a Constituição da República Federativa do Brasil de 1988; A carta de Orientação aos técnicos do CREAS e o Estatuto da Criança e do Adolescente (ECA), sendo conteúdos que não são vistos nas universidades nos cursos de Pedagogia.

O que destacamos na pesquisa e nas discussões ao longo do artigo é apontar o espaço de atuação do pedagogo além da sala de aula, como também a precária formação quanto a compreensão dos diversos ambientes em que estes profissionais poderiam contribuir. Um percentual bem maior desses profissionais está nas escolas, pela demanda que é bem ampla. $\mathrm{O}$ que favorece que as políticas educacionais se prendem à educação escolar, deixando a cargo de outros setores profissionais demarcarem o papel do educador.

\section{Considerações finais}

As pesquisas acerca da atribuição do pedagogo no âmbito da Assistência Social, especificamente no CREAS, proporcionaram-nos uma percepção maior sobre o que foi 
constituído tradicionalmente na história da educação brasileira e o que ainda ficou no imaginário das pessoas, a limitação de atuação do pedagogo em espaços apenas escolares, notase que após a determinação que vem proposta nas DCNS (2006) do Curso Pedagogia, que foi através desta reformulação na área de atuação do pedagogo, que seu campo de atuação foi ampliado para outras camadas educacionais e profissionais. Ficou salientada nesta pesquisa a compreensão de que a formação do Pedagogo é muito limitada ao ambiente escolar, ou como pedagogos entendemos que as teorias utilizadas no ambiente escolar não estão sendo ampliadas para a educação, âmbito maior da área de formação de um pedagogo.

A tentativa de alargar o pensamento sobre a atuação do Pedagogo possibilitou que fosse incluído o Pedagogo em outros espaços não escolares, nos quais são necessários o conhecimento pedagógico. Importante, nesse momento de reflexão, que sempre sejam abertas as discussões nos espaços acadêmicos sobre o conhecimento pedagógico atrelado às demandas sociais.

Assim, diante das análises apresentadas foi possível perceber a importância da atuação do Pedagogo na Assistência, como colaborador na inserção das crianças e dos adolescentes na sociedade que passaram por uma situação de risco ou de violação de direito. O olhar da plenitude do desenvolvimento do ser humano deve ser preservado e para isso a Constituição Brasileira descreve os direitos fundamentais e invioláveis. Conforme o Estatuto da Criança e do Adolescente (ECA), Art. $3^{\circ}$, que institui que a criança e o adolescente gozem de todos os direitos fundamentais.

Com isso, a Assistência Social vem promover reivindicar a garantia dessa plenitude e lutar através de um olhar esclarecido partindo da equipe técnica do CREAS, sendo este pelo Assistente Social, a Psicóloga, o Pedagogo e o Advogado, cada um com sua especificidade formando um trabalho em conjunto.

O resultado do estudo apontou que apesar das Diretrizes Nacionais do Curso Pedagogia e DCNS apontarem para essa ampliação do espaço de atuação do pedagogo, é preciso alargar esse campo de estudo, entrar nos palcos de debate acerca da atuação do Pedagogo na Assistência Social, sendo estes em ambientes educativos, nas salas de aulas em universidades, no que a cada momento de discussão esse desempenho é aprimorado.

\section{Referências}


ARAÚJO, Lilian Cristina Santos. A atuação do pedagogo no campo jurídico. Pará: VI Jornada Internacional de Política Pública, 2013.

ARAÚJO, Rose Mary de Souza. Escola Normal da Parahyba do Norte: movimento de constituição da formação de professores no século XIX. João Pessoa: UFPB, 2010.

ASTRIS, Wany. Atribuições e Áreas de Atuação do Pedagogo, 2013. Disponível em: http://wanypedagogia.blogspot.com.br/p/atribuicoes-e-areas-de-atuacao-do.html. Acesso em: 06 nov. de 2017.

BRASIL. Lei Orgânica da Assistência Social. Lei no 8.742, de 7 de dezembro de 1993. Disponível em: http://www.planalto.gov.br/ccivil_03/leis/L8742compilado.htm>. Acesso em: 10 nov. de 2107.

BRASIL. Conselho Nacional de Assistência Social (CNAS). Resolução n ${ }^{\circ}$. 9, de 15 de abril de 2014. Diário Oficial da União. Disponível em:

file://C:/Users/Marciacfmendes/Downloads/CNAS\%202014\%20-\%20009\%20-

\%2015.04.2014\%20(1).pdf. Acesso em: 18 de fevereiro de 2018.

BRASIL. Estatuto da Criança e Adolescente. Lei nº 8.069, de 13 de julho de 1990.

BRASIL. Orientações Técnicas: Centro de Referência Especializado de Assistência Social CREAS, Brasília, 2011.

BRASIL. Política Nacional de Assistência Social. Norma Operacional Básica. 2004.

Disponível em:

http://www.mds.gov.br/webarquivos/publicacao/assistencia_social/Normativas/PNAS2004.pd f>.Acesso em: 10 nov. de 2017.

BRASIL. Ministério da Saúde. D.O.U. de 05/04/1977 . Seção I, Parte I, p. 3929

BRASIL. Resolução CNE/CP 1/2006. Diário Oficial da União, Brasília, 16 de maio de 2006, Seção 1, p. 11.

CECCIM, R. B. \& Fonseca, E. S. Atendimento pedagógico-educacional hospitalar: promoção do desenvolvimento psíquico e cognitivo da criança hospitalizada. In: Temas sobre Desenvolvimento, v.8, n.44, p. 117, 1999.

LIBÂNEO, José Carlos. Didática. São Paulo: Cortez, 2006.

LIBÂNEO, José Carlos. Pedagogia e Pedagogos para Quê? 4 $4^{\mathrm{a}}$ edição. São Paulo, Cortez, 2001.

LIBÂNEO, José Carlos. Pedagogia e pedagogos: inquietações e buscas. Texto de conferência escrito para o $2^{\circ}$ Encontro Cearense de Educadores, promovido pelo OfinArtes - Centro de Acessória Pedagógica, Fortaleza, 1999.

LOPES, Eliane Marta Teixeira; FILHO, Luciano Mendes Faria; VEIGA, Cynthia Greive. 500 Anos de Educação no Brasil. Belo Horizonte: Autêntica,2a ed., 2000. 
MACHADO, Érico Ribas. RODRIGUES, Marli de Fátima; SEVERO, José Leonardo Rolim. Pedagogia, Pedagogia Social e educação Social no Brasil: entrecruzamentos, tensões e possibilidades. Aracaju: Interfaces Cientificas, v.3, n.1, p. 11-20, 2014.

MINAYO, Maria Cecília de Souza. Análise qualitativa: teoria, passos e fidedignidade. Ciênc. saúde coletiva [online], v.17, n.3, p.621-626, 2012. Disponível em:

https://www.scielo.br/scielo.php?pid=S141381232012000300007\&script=sci_abstract\&tlng= pt. Acesso em: 28 de abr. de 2021.

OLIVEIRA, Dalila. (Org.). Gestão democrática da educação: desafios contemporâneos. Petrópolis, RJ: Vozes, 1997.

PEREIRA, Lucila Conceição. Pedagogo, (s.a.). Disponível em:

http://www.infoescola.com/profissoes/pedagogo/. Acesso em 07 nov. de 2017.

PRADO JR., Caio. Evolução política do Brasil. São Paulo: Editora Brasiliense, $1^{\text {a }}$ reimpressão, 1999.

SANTOS, Karine; PAULA, Ercilía Maria Angeli Teixeira de. A teoria de Paulo Freire Como Fundamento da Pedagogia Social. Aracaju: Interfaces Cientificas, v.3, n.1, p. 33-44, 2014.

SILVA, Nação Luiz. Pedagogia empresarial: valorizando saberes, qualificando práticas, formando referências!, 2012 Disponivel em:

http://monografias.brasilescola.uol.com.br/pedagogia/pedagogia-empresarial-valorizandosaberes-qualificando-praticas.htm>.Acesso em: 08 de nov. de 2017.

SOUZA, Cleia Renata Teixeira de. Et al. A Atuação Profissional e Formação do Educador Social no Brasil: uma roda de conversa. Aracaju: Interfaces Cientificas, v.3, n.1, p. 77-88, 2014.

SAVIANI, Demerval. História das ideias pedagógicas no Brasil, Campinas: Autores Associados, 2007. Disponível em: https://pt.scribd.com/doc/109581719/SAVIANI-DermevalHistoria-das-ideias-pedagogicasno-Brasil-Campinas-Autores-Associados-2007\#. Acesso em: 10 nov. de 2017.

SAVIANI, Demerval. Concepção Pedagógica Tradicional. Disponível em: http://www.histedbr.fae.unicamp.br/navegando/glossario/verb_c_concepcao_pedagogica_ tradicional.htm. Acesso em: 10 de nov. 2017.

SAVIANI, Demerval. As concepções pedagógicas na história da educação brasileira. Campinas: CNPQ, 2005. Texto elaborado no âmbito do projeto de pesquisa "O espaço acadêmico da pedagogia no Brasil", financiado pelo CNPq, para o "Projeto 20 anos do Histedbr". Campinas, 25 de agosto de 2005.

SAVIANNI, Demerval. História das Ideias Pedagógicas no Brasil. Campinas: Autores Associados, 2013. 
SCHULTZ, Theodore W. O Capital Humano: Investimentos em Educação e Pesquisa. Zahar Editores, Rio de Janeiro, 1971. OARES, Laura, Tavares Ribeiro. O desastre social. Rio de Janeiro: Recorde, 2003.

SILVA, Delcio Barros. As Principais Tendências Pedagógicas na Prática Escolar Brasileira e seus Pressupostos de Aprendizagem, (s.a) Disponível em:

http://www.ufsm.br/lec/01_00/DelcioL\&C3.htm. A isso em: 08 de nov. de 2017. 